\title{
Words Both Kind and Contrary
}

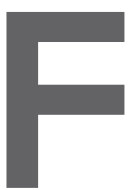

OR THE FIRST time in many, many years I found Communications (July 2008) both friendly to the reader and useful. Over the years, the physical form and font of the issues were very unfriendly, let alone the content, which was quite rarified. Not this latest issue. The redesign makes the physical attributes-paper (non-glossy, yeah!), layout, and font very approachable. And the content is just great. Real concrete stuff to learn and use!

Makes me happy to have persevered as a member during the past 10 years!

Deepak Kenchammana, San Jose, CA

Thanks for the good work in revising Communications for readability and attractiveness. The new online format is very compelling as well. Readability for me is way up, and I like the catchy use of color.

Well done!

Alex Lancaster, Arlington, VA

I don't have time to adequately express my thoughts on the new design for Communications. About all I can say is, "Wow, I am impressed!" The content is so rich. Definitely a better magazine.

Thank you!

David Brown, Denver, PA

I received my print copy of the July Communications and wanted to let

\section{Coming Next Month in}

\section{COMMUNICATIONS}

Information Integration

in the Enterprise

Design and Code Reviews

in the Internet Age

Beyond Google: Automated Question Answering on the Web

How Do I Model State?

Plus the latest news on spectral graph theory, video encoding, and privacy technologies. you know how much I dislike the new three-column layout and reduced font size. I have been a member of ACM for over 25 years and have always enjoyed thumbing though every issue of $\mathrm{Com}^{-}$ munications, reading articles here and there. Trying to read the new version was not enjoyable.

Has your design team forgotten that a lot of us ACM members are in our 50s, 60s, and 70s, and can't comfortably read small, wedged-together print?

Judy Walters, Naperville, IL

\section{Catalan Is a Different Latin Language}

I found it astonishing that the article "Web Searching in a Multilingual World" by Wingyan Chung (May 2008) included (in Table 2) the following claim: "Catalan (another version of Spanish) is widely used as well." A language spoken in the same country as another language is not necessarily "a version" of the other language. Catalan is, like French, Spanish, and Italian, a "different" Latin language, spoken not only in Spain but also in France and Andorra where it is the official language.

Alberto Gonzalez Tellez,

Valencia, Spain

\section{Behavior Reinforcement is \\ an Empirical Issue}

Although the concepts were presented correctly in the section called "Feedback and learning from security-related decisions" in Ryan West's article "The Psychology of Security" (Apr. 2008), the definitions were incorrect. Reinforcements, both positive and negative, motivate behavior. The nagging messages regarding, say, Windows update availability can be seen as negative reinforcement. Users then update the operating system, and the message goes away. The same users would be more likely to update in the future if the message itself were, indeed, reinforcing.

Consequences that inhibit certain behavior are punishments, either positive (something "good" happens) or negative (something "bad" is re- moved). Nothing should be assumed in advance to be reinforcing or punishing. Determining which is which is always an empirical issue. Only by studying how users actually respond to feedback from the interface can system developers truly understand how the interface affects their behavior. Otherwise, like a school principal wondering why students sent regularly to the "office" for "punishment" continue to misbehave, they will be left scratching their heads.

Timothy Dunnigan, San Diego, CA

Author's Response:

Thanks to Dunnigan for the correction. The distinction simply slipped my mind.

Ryan West, Round Rock, TX

\section{The Price of Eternal Vigilance}

Essentially the same quote was attributed to two different people, one in an article, the other in a column, in the same issue (Mar. 2008). The article "The Illusion of Security" by David Wright et al. ended with: "As Thomas Jefferson said, 'The price of freedom is eternal vigilance." The "Inside Risks" column by Xiaming Lu and George Ledin, Jr., began with: "When Wendell Phillips...told a Boston audience in 1852 that 'Eternal vigilance is the price of liberty'..."

A bit of Google-sleuthing found that although the quote is sometimes attributed to Jefferson, Tom Paine, and Patrick Henry, its first documented use was probably by Phillips (Bartleby. com's Dictionary of Quotations, www. bartleby.com/73/1073.html).

Further muddying the issue, wikiquote.org (en.wikiquote.org/wiki/ Leonard_H._Courtney) claims the quote originated with Leonard Henry Courtney (1832-1918), a British baron, politician, and statistician.

Jeff Johnson, San Francisco

Communications welcomes your opinion. To submit Letter to the Editor, please limit your comments to 500 words or less and send to letters@cacm.acm.org. 